\title{
OS DADOS SOBRE RELIGIÕES NO BRASIL EM DEBATE
}

\author{
Faustino Teixeiral
}

A antropóloga Clara Mafra tem atuado de forma muito positiva nas reflexôes sobre os números censitários sobre religião, fornecidos pelo Instituto Brasileiro de Geografia e Estatística (IBGE). Podem-se destacar três artigos em que a autora se debruçou sobre essa questão: Censo de religiāo: um instrumento descartável ou reciclável (Mafra, 2004); Números e Narrativas (Mafra, 2013a) e $O$ que os homens e as mulheres podem fazer com números que fazem coisas (Mafra, 2013b). São artigos que indagam sobre os dados do levantamento censitário como "instrumento de conhecimento".

Países como França e Estados Unidos já não fazem há tempos esse levantamento censitário das religiōes, embora importantes centros de pesquisa, como o Pew Research Center, de Washington, D.C., continuem apresentando relatórios sobre as religiões mundiais, como ocorreu em 2012, em coincidência com a divulgação dos dados do IBGE sobre as religiōes no Brasil. No Brasil, ao contrário, esse levantamento vem sendo feito, com uma breve interrupção entre 1920 e 1930, desde 1872. Clara Mafra ressalta essa "longevidade" dos números sobre religião no país, traduzindo uma viva "memória continuada".

Não se pode omitir a importância dos dados apresentados pelo censo para aferir o campo religioso brasileiro, mas o que vem revelado é apenas "um instantâneo sobre a situação que ele visa" (Sanchis, 2013), uma "fotografia da autodeclaração religiosa em determinado contexto" (Menezes, 2012, p. 42). O que ele possibilita é uma "imagem do Brasil" a cada dez anos, mas que deixa escapar os "movimentos finos" que envolvem a presença e circulação das religiōes no campo em questão. Daí muitos analistas insistirem na importância de uma exploração mais qualificada, com base em pesquisas qualitativas que possam agregar outras variáveis para a análise a ser empreendida.

1 Professor do Programa de Pós-Graduação em Ciência da Religião da Universidade Federal de Juiz de Fora (UFJF). E-mail: fteixeira@uai.com.br

Debates do NER, Porto Alegre, Ano I4, N. 24, P. 77-84, JUl./Dez. 2013 
Muitas críticas foram tecidas depois da atrasada divulgação dos dados sobre religióes no Brasil pelo IBGE, ao final de junho de 2012. Não poucos analistas revelaram suas dificuldades com a metodologia de classificação das religiōes adotada pelo IBGE (Altmann, 2012). Falou-se também das vicissitudes na captação da "dinâmica religiosa" do país (Menezes, 2013), da imprecisão no afinamento do instrumental para compreender o campo religioso protestante, bem como o fenômeno das múltiplas pertenças, dos fluxos e trânsitos religiosos ou os sincretismos menos visíveis (Campos, 2013; Lewgoy, 2013; Almeida; Barbosa, 2013).

Clara Mafra está bem ciente destas dificuldades, e avança ainda outras questões, como o "ato político" que acompanha a própria realização de um censo. Os números não são neutros, não há dúvida. Eles conformam identidades sociais, como bem lembra essa autora. Ela pôde acompanhar o processo de trabalho das equipes do Instituto de Estudos da Religião (ISER) na assessoria ao IBGE, com respeito às informações preliminares fornecidas, isso nos dois últimos censos, de 2000 e 2010. Sugeriram-se "alternativas e soluçōes aos problemas apresentados", mas o acesso preliminar aos dados não foi favorecido. Como lembra Mafra, "nas duas ocasiōes, o IBGE teve uma postura ética discutível: proibiu até o último momento o acesso aos números do censo atual para os parceiros do ISER, mas divulgou com alguns dias de antecedência as informações para alguns órgãos da imprensa" (Mafra, 2013b).

Em seu texto Números e narrativas, Mafra reconhece que nessa longa história o IBGE desenvolveu uma "metodologia de ponta e de qualidade internacional”, o que não significa carência de problemas ou desvios que precisam ser corrigidos. Há ainda "escassez de informaçôes empíricas", o que dificulta ou mesmo interdita uma análise mais precisa sobre o campo religioso no país. Mafra corrobora, na verdade, a ideia defendida por muitos a respeito da necessidade de a reflexão ser acompanhada por pesquisas qualitativas consistentes, mas adverte sobre a importância de um trabalho contínuo visando a superar "essa precariedade na produção de informações censitárias". Aponta algumas sugestôes para melhorar a qualidade da informação fornecida pelo IBGE, evitando as recorrentes dúvidas aventadas por analistas, relacionadas com as questôes que suscitam debate: "múltiplos pertencimentos", "sem

Debates do NER, Porto Alegre, ANo I4, N. 24, P. 77-84, JUl./DEZ. 2013 
religião", "evangélicos não determinados" etc. Isso envolveria uma melhora ou aperfeiçoamento da grade de alternativas, bem como a inserção de questão que pudesse indicar mais precisamente a "frequência da participação em reuniões, eventos ou rituais da religião ou culto" (Mafra, 2013a).

Clara Mafra toca em algumas "aporias" bem precisas, que indicam a real complexidade que acompanha a avaliação correta do campo religioso brasileiro. Uma delas relaciona-se com a baixíssima declaração de múltiplos pertencimentos no último censo: 15.379 pessoas. Esses dados esbarram, por exemplo, na ideia propalada de "trânsito religioso". Talvez seja mais correto afirmar que os declarantes estão resistindo a indicar sua múltipla pertença. A autora relativiza também certas interpretações que concluem, a partir do crescimento dos "evangélicos não determinados", que as pessoas estão participando do religioso num sentido mais alargado. Para dar conta do modo de pertença e do fluxo que acompanha o campo das religiōes no Brasil, Mafra propõe a substituição da "metáfora do mapa", mais usual, pela "metáfora do holograma", capaz de traduzir melhor a dinâmica e o movimento das religiōes no Brasil. É uma metáfora que, a seu ver, propicia o acolhimento de "operaçōes mais ousadas e flexíveis com os números". O que a autora propõe, na verdade, é a possibilidade de canais analíticos mais abertos, "capazes de conviver com alguma incerteza e imprevisibilidade" (Mafra, 2013a).

Essa nova metáfora poderia ajudar a compreender, por exemplo, esse curioso fenômeno da diminuição, em números absolutos, na declaração de pertença dos adeptos da Igreja Universal do Reino de Deus (IURD), que passaram de 2,1 milhões para cerca de 1,9 milhão na última década, queda que aconteceu igualmente com a declaração de pertença da tradicional Congregação Cristã do Brasil, bem como da Igreja do Evangelho Quadrangular. Com respeito à situação da IURD, são aventadas várias hipóteses para o decréscimo apresentado. Fala-se na presença concorrencial de novas pentecostais, como a Igreja Mundial do Poder de Deus, no "desgaste da fórmula da Universal", ou na redução da declaração pentecostal em razão do "inchaço" da categoria "evangélica não determinada". Clara Mafra tende a relativizar esse "input negativo" que aponta para um certo teto na expansão da Universal. Sinaliza que o traço peculiar da IURD reside em sua "membresia

Debates do NER, Porto Alegre, ANo I4, N. 24, P. 77-84, JUl./Dez. 2013 
flutuante", bem distinto do que ocorre com o modelo congregacional cristão reformado. As formas de pertença são distintas e a dinâmica de adesão comunitária é mais "frouxa". Isso significa que participantes da IURD poderiam, sem problemas, transitar por um "circuito variado de igrejas", o que escapa da "topografia unidimensional" envolvida na tradicional metáfora do mapa. Esses "movimentos finos" escapam da ocular do censo, que opera mais "a partir de conjuntos amplos, fixos e homogêneos" (Menezes, 2013). Como indica Mafra, "a Universal tem um desenho institucional que não se abala com a não fidelização do frequentador", e seus membros esporádicos podem, sem problemas, identificar-se como "evangélicos não determinados". A metáfora do holograma, segundo a autora, consegue captar melhor esse traço mais plural que tende a animar as experiências religiosas no âmbito cristão, no exercício de busca de novas alternativas "às vidas congregacionais de vínculo forte" (Mafra, 2013a).

O mesmo ocorre na abordagem dos "sem religião", segundo os dados do último censo. Como era de se esperar, essa categoria envolve mais uma adesão masculina e jovem, com idade média de 26 anos, num universo mais urbano que rural. Mas, para a surpresa dos analistas, e fugindo do "padrão sociológico moderno", boa parte dos "sem religião" tem baixa escolaridade. Há entre eles uma presença significativa de pardos e negros e, em termos de rendimento mensal domiciliar, são quase $60 \%$ de declarantes que se encontram na faixa de vencimentos de até um salário mínimo. Essa categoria poderia também envolver, curiosamente, jovens pentecostais de periferia desencaixados da prática evangélica tradicional, considerados "desviados" em razão de seu afastamento da igreja (Mafra, 2013a). Analistas apontam também a presença dos "sem religião" entre aqueles que se situam no "circuito neoesotérico" e mesmo entre os que estão englobados na categoria de tradições indígenas. E, dentre os "sem religião", os agnósticos e ateus constituem uma minoria, já que grande parte de seus declarantes professam "alguma crença em um ser ou energia superior", ainda que distanciados das "atividades de culto e louvor de modo sistemático" (Mafra, 2013a). Mais uma vez, a metáfora do holograma é mais propícia para ajudar nessa móvel configuração da religiosidade.

Debates do NER, Porto Alegre, ANo I4, N. 24, P. 77-84, JUl./DEZ. 2013 
Outro dado complexo na interpretação dos dados do censo diz respeito à declaração de crença espírita e afro-brasileira. Se de um lado verifica-se o crescimento dos espíritas na última década (de 1,3\% para 2,0\%), as religiōes afro-brasileiras permanecem estacionadas na faixa de $0,3 \%$ da população brasileira. O censo de 2010 revelou uma modesta recuperação do crescimento dessas tradições, que até então vinham perdendo adeptos. Na última década, a umbanda ganhou 9.900 novos adeptos, enquanto o candomblé ganhou 28.000. O censo não consegue, porém, captar a real presença do espiritismo ou das religiões afro-brasileiras, por diversas razôes. As realidades "objetiváveis" conseguem melhor guarida no instrumental adotado, mas o que é flutuante e impreciso, como acontece na prática religiosa em curso, foge desse controle. É o que se dá no terreno das múltiplas pertenças, das práticas devocionais não identitárias e dos sincretismos pouco visíveis, que pontuam as religiōes mediúnicas, sobretudo as de matriz africana. Em relatório de pesquisa promovido pela Arquidiocese de Belo Horizonte, por ocasião do "Projeto Construir a Esperança" (1991), constatou-se que 54,8\% dos católicos praticantes acreditam na reencarnação. E, como assinala Reginaldo Prandi, "boa parte dos afro-brasileiros está escondida nas rubricas 'católico' e 'espírita”" (Prandi, 2013b). A sociedade brasileira está marcada pela presença de "espíritos", não há dúvida. Não são poucos aqueles que vivem a experiência de transe regular ou a comunicação personalizada com entidades do "outro mundo". Trata-se de uma realidade que envolve cerca de metade da população brasileira, como indicou Gilberto Velho:

Transe, possessão e mediunidade são fenômenos religiosos recorrentes na sociedade brasileira. No candomblé, na umbanda, no espiritismo, no pentecostalismo e em outros grupos religiosos, entidades, espíritos, guias, o Espírito Santo, orixás descem ou sobem, se incorporam, se comunicam etc. através de cavalos, aparelhos, ou do que costumamos denominar de indivíduo agente empírico, unidade significativa da sociedade ocidental moderna nos termos de Louis Dumont (Velho, 2003, p. 53; Sanchis, 1994, p. 37; Carvalho, 1992, p. 146).

Os parcos dados do censo sobre as religiōes afro-brasileiras não traduzem o singular lugar dessas tradições "na construção permanente da cultura brasi-

Debates do NER, Porto Alegre, ANo I4, N. 24, P. 77-84, JUl./Dez. 2013 
leira não religiosa", seja no âmbito da música, dos ritmos, danças, literatura e poesia, cinema, culinária, estética e imaginário mítico (Prandi, 2013a).

Ao final de seu texto, Clara Mafra sinaliza que o catolicismo deixou de ser "a única alternativa de religião" dos brasileiros, embora permaneça como uma importante referência no país. O que ocorre, na verdade, é uma afirmação cada vez mais presente de uma "religiosidade alargada", de uma "religiosidade cristã em fluxo", com destaque para a irradiação pentecostal, e de um pentecostalismo entendido como organismo ágil e de forte capilaridade. Mafra destaca "a capacidade dos evangélicos de criar malhas institucionais sem centros ou com múltiplos centros, com ênfase na subjetividade e na capacidade de autogestão" (Mafra, 2013a).

Trata-se de um texto provocador, que levanta pistas interessantes e sugestivas para o incentivo de novas perspectivas de abordagem sobre as religióes no Brasil, de teorias mais abertas e alargadas para conseguir dar conta de um campo que se revela cada vez mais pluralizado, ambíguo e diferenciado, com nuances peculiares que escapam ao olhar mais habituado aos mapas fixos e homogêneos.

\section{REFERENNCIAS}

ALMEIDA, Ronaldo de; BARBOSA, Rogério. Transmissão religiosa nos domicílios brasileiros. In: TEIXEIRA, Faustino; MENEZES, Renata (Orgs.). Religióes em movimento: o censo de 2010. Petrópolis: Vozes, 2013. No prelo.

ALTMANN, Walter. Censo IBGE 2010 e religião. Horizonte, v. 10, n. 28, p. 1122-1129, 2012.

CAMPOS, Leonildo Silveira. "Evangélicos de missão" em declínio no Brasil: exercícios de demografia religiosa à margem do Censo de 2010. In: TEIXEIRA, Faustino; MENEZES, Renata (Orgs.). Religióes em movimento: o censo de 2010. Petrópolis: Vozes, 2013. No prelo. 
CARVALHO, José Jorge de. Características do fenômeno religioso na sociedade contemporânea. In: BINGEMER, Maria Clara L. (Org.). O impacto da modernidade sobre a religiāo. São Paulo: Loyola, 1992. p. 133-163.

LEWGOY, Bernardo. A contagem do rebanho e a magia dos números: notas sobre o espiritismo no censo de 2010. In: TEIXEIRA, Faustino; MENEZES, Renata (Orgs.). Religióes em movimento: o censo de 2010. Petrópolis: Vozes, 2013. No prelo.

MAFRA, Clara. Censo de religião: um instrumento descartável ou reciclável? Religiāo e Sociedade, v. 24, n. 2, p. 152-159, 2004.

MAFRA, Clara. Números e narrativas. Debates do NER, Porto Alegre, n. 24, 2013a.

MAFRA, Clara. O que os homens e as mulheres podem fazer com números que fazem coisas. In: TEIXEIRA, Faustino; MENEZES, Renata (Orgs.). Religiöes em movimento: o censo de 2010. Petrópolis: Vozes, 2013b. No prelo.

MARIZ, Cecília L.; GRACINO JR, Paulo. As igrejas pentecostais no censo de 2010. In: TEIXEIRA, Faustino; MENEZES, Renata (Orgs.). Religiōes em movimento: o censo de 2010. Petrópolis: Vozes, 2013. No prelo.

MENEZES, Renata. Censo 2010, fotografia panorâmica da vida nacional. Cadernos IHU em formação, ano VIII, n. 45, p. 40-44, 2012.

MENEZES, Renata. Às margens do Censo 2010: expectativas, repercussōes, limites e usos dos dados de religião. In: TEIXEIRA, Faustino; MENEZES, Renata (Orgs.). Religióes em movimento: o censo de 2010. Petrópolis: Vozes, 2013. No prelo.

NOVAES, Regina. Jovens "sem religião": sinais de outros tempos. In: TEIXEIRA, Faustino; MENEZES, Renata (Orgs.). Religióes em movimento: o censo de 2010. Petrópolis: Vozes, 2013. No prelo.

PRANDI, Reginaldo. Sobre as religiōes afro-brasileiras. Horizonte, v. 11, n. 29, p. 10-12, 2013a. 
PRANDI, Reginaldo. As religiōes afro-brasileiras em ascensão e declínio. In: TEIXEIRA, Faustino; MENEZES, Renata (Orgs.). Religiōes em movimento: o censo de 2010. Petrópolis: Vozes, 2013b. No prelo.

SANCHIS, Pierre. O repto pentecostal à "cultura católico-brasileira”. In: ANTONIAZZI, Alberto et al. Nem anjos nem demônios. Interpretaçôes sociológicas do pentecostalismo. Petrópolis: Vozes, 1994. p. 34-63.

SANCHIS, Pierre. Prefácio. In: TEIXEIRA, Faustino; MENEZES, Renata (Orgs.). Religióes em movimento: o censo de 2010. Petrópolis: Vozes, 2013. No prelo.

TEIXEIRA, Faustino; MENEZES, Renata (Orgs.). Religiōes em movimento: o censo de 2010. Petrópolis: Vozes, 2013. No prelo.

VELHO, Gilberto. Projeto e metamorfose. Antropologia das sociedades complexas. 3. ed. Rio de Janeiro: Jorge Zahar, 2003. 